\title{
A SIMPLE AND RELIABLE PCR-RESTRICTION FRAGMENT LENGTH POLYMORPHISM ASSAY TO IDENTIFY CANDIDA ALBICANS AND ITS CLOSELY RELATED CANDIDA DUBLINIENSIS
}

\author{
Yi Ping Ge, Le Wang, Gui Xia Lu, Yong Nian Shen, Wei Da Liu*
}

Department of Medical Mycology, Institute of Dermatology, Chinese Academy of Medical Sciences, Nanjing, Jiangsu Province, China.

Submitted: December 02, 2010; Returned to authors for corrections: May 05, 2011; Approved: June 07, 2012.

\begin{abstract}
Candida dubliniensis is an emerging pathogen capable of causing superficial as well as systemic infections. Due to its close similarity to $C$. albcians, conventional methods based on phenotypic traits are not always reliable in identification of $C$. dubliniensis. In this study, we developed a PCR-restriction fragment length polymorphism (RFLP) assay to identify and discriminate between the two closely related species. The D1/D2 region of $28 \mathrm{~S}$ rDNA was amplified by PCR and enzymatically digested by ApaI and BsiEI respectively. PCR products of both species were digested into two fragments by $A p a \mathrm{I}$, but those of other yeast species were undigested. BsiEI cut the PCR products of C. albicans into two fragments but not those of C. dubliniensis. Thus two species were differentiated. We evaluated 10 reference strains representing 10 yeast species, among which C. albicans and C. dubliniensis were successfully identified. A total of 56 phenotypically characterized clinical isolates (42 C. albicans isolates and 14 C. dubliniensis isolates) were also investigated for intraspecies variability. All tested isolates produced identical RFLP patterns to their respective reference strains except one initially misidentified isolate. Our method offers a simple, rapid and reliable molecular method for the identification of $C$. albicans and C. dubliniensis.
\end{abstract}

Key words: Candida albicans, Candida dubliniensis, PCR-restriction fragment length polymorphism, identification, differentiation

\section{INTRODUCTION}

Candida species usually reside as commensals at mucosal membranes in healthy individuals and can be detected in approximately $50 \%$ of the population in this non-virulent form. However, under conditions when the host's normal flora is disrupted or the immunity is impaired, Candida species often become pathogenic. Candida infections have become a problem of growing significance. The incidence of infections has increased dramatically over the past a few decades. $C$. albcians is the most common pathogen in this genus and fourth leading cause of nonsocomial bloodstream infections $(4,21)$. However, several non-albicans Candida species, e.g. $C$. glabrata, C. tropicalis and C. parapsilosis, have emerged as causative agents of candidiasis (20). Another Candida species of growing clinical importance is C. dubliniensis, a novel

*Corresponding Author. Mailing address: Department of Medical Mycology, Institute of Dermatology, Chinese Academy of Medical Sciences, Nanjing, Jiangsu Province, China.; E-mail: liumyco@hotmail.com 
opportunistic pathogen first described as a distinct taxon by Sullivan in 1995 (26). C. dubliniensis was mainly associated with oropharyngeal candidiasis in HIV-infected patients. Recent evidence, however, indicates that it is also a cause of superficial and systemic infections in HIV-negative individuals with an estimated prevalence rate below $5 \%(7,10,27)$. It is important to study the epidemiology of $C$. dubliniensis due to its capability of rapid acquisition of stable fluconazole resistance, both in vitro and in vivo, after prolonged therapy in HIV-seropositive patients $(15,16,24)$.

Identification of $C$. dubliniensis can be problematic due to its close phenotypic similarity to $C$. albicans. Both species produces germ tubes, chlamydospores and true hyphae (26). Several phenotypic assays have been developed to differentiate C. dubliniensis from C. albicans, including the capacity to grow at $45^{\circ} \mathrm{C}$, formation of chlamydospores on selected media, the ability to assimilate xylose, lactate or $\alpha$-methyl-D-glucoside and different colony color produced on CHROMagar Candida medium $(2,5,23,28)$. These assays can serve as rapid methods to screen for potential $C$. dubliniensis isolates. But none of these assays have proved to be efficient and entirely reliable. At present, the most accurate means of differentiating between these two closely related species requires the use of molecular biology-based techniques, such as electrophoretic karyotyping, DNA fingerprinting analysis with repetitive sequencecontaining DNA probes, randomly amplified polymorphic DNA analysis, restriction fragment length polymorphism (RFLP), amplified fragment length polymorphism, conventional and real-time PCR analysis, or pulsed-field gel electrophoresis $(18,25)$. These methods proved very effective. Among them, PCR-RFLP analysis is a simple and reliable one. In this study we developed and evaluated a PCR-RFLP assay to identify and discriminate between $C$. albicans and $C$. dubliniensis.

\section{MATERIALS AND METHODS}

\section{Yeast Strains}

C. albicans (SC 5314), C. dubliniensis (CBS 7987), C. glabrata (ATCC 2001), C. guilliermondii (CBS 6021), C. krusei (ATCC 6258), C. kefyr (CBS 6432), C. lusitaniae (CBS 6936), C. parapsilosis (ATCC 22019), C. tropicalis (CBS 8072) and Trichosporon asahii (CBS 2479) were used as reference yeast strains. Fourteen clinical isolates of presumptive $C$. dubliniensis originating from sputum $(\mathrm{n}=10)$, vaginal swabs $(n=3)$ and urine $(n=1)$ were studied in comparison with 42 clinical strains of $C$. albicans. Presumptive C. dubliniensis isolates were characterized by phenotypic methods including growth on cornmeal Tween-80 agar, growth at $45^{\circ} \mathrm{C}$, characteristic growth on CHROMagar Candida (CHROMagar, Paris, France) and confirmed by Vitek 2 system (biomerieux, Marcy l'Etoile, France).

\section{Culture Conditions and Genomic DNA Extraction}

Yeast cells were cultured on YPD broth (1\% yeast extract, $2 \%$ peptone, and $2 \%$ dextrose) and were incubated for $24-36$ hours at $30^{\circ} \mathrm{C}$ under shaking conditions (200rpm). The yeast cells were collected by centrifugation $(2 \mathrm{ml}$ of the broth culture at $12000 \times \mathrm{g}$ for $2 \mathrm{~min}$ ), suspended in $600 \mu \mathrm{l}$ of $1 \mathrm{M}$ sorbitol-50 $\mathrm{mM}$ phosphate buffer $(\mathrm{pH}$ 7.5) containing 50U Lyticase (Sigma-Aldrich, US). After $30 \mathrm{~min}$ of incubation at $30^{\circ} \mathrm{C}$, the cells were centrifuged at $1500 \times \mathrm{g}$ for $10 \mathrm{~min}$. The supernatant was then discarded and pellet was collected. TianGen Yeast Genomic DNA Extraction Kit (TianGen Biotech, Beijing, China) was used to extract genomic DNA from tested isolates by following the enclosed protocol. DNA obtained was finally suspended in $100 \mu \mathrm{TE}$ buffer and stored at $-20^{\circ} \mathrm{C}$ before use.

\section{Sequence Analyses and Selection of Restriction Enzymes}

A total of 30 sequences of the $28 \mathrm{~S}$ ribosomal DNA (rDNA) D1/D2 region of 10 tested yeast species were retrieved from GenBank database (data not shown). Each sequence was then analyzed for restriction sites using the MapDraw program of DNA Star Lasergene Version 7.0. Restriction enzymes were selected as to generate C. albcians-specific and C. dubliniensisspecific RFLP patterns. 


\section{PCR Amplification of the D1/D2 region}

Primers NL-1 (5'-GCATATCAATAAGCGGAGGAAA AG-3') and NL-4 (5'-GGTCCGTGTTTCAAGACGG-3') were used to amplify D1/D2 region of the $28 \mathrm{~S}$ rDNA genes. PCR amplifications were carried out in $50-\mu$ l volumes containing $1.5 \mu \mathrm{l}$ of each $10 \mu \mathrm{mol} / 1$ primer, $25 \mu \mathrm{l}$ of GoTaq Green Master Mix (Promega, Madison, WI, USA), $3 \mu$ I DNA template and corresponding amount of ultra-pure distilled water. PCR was performed in a PTC-200 DNA Engine thermal cycler (BioRad) with following parameters: $94^{\circ} \mathrm{C}$ for $3 \mathrm{~min}$; $94^{\circ}$ for $1 \mathrm{~min}$, $52^{\circ} \mathrm{C}$ for $30 \mathrm{~s}$ and $72^{\circ} \mathrm{C}$ for $1 \mathrm{~min}$, repeated for a total of 32 cycles; $72^{\circ} \mathrm{C}$ for $10 \mathrm{~min}$ and $4^{\circ} \mathrm{C}$ hold.

\section{Restriction Digests of PCR Products}

RFLP analyses were performed in $20 \mu$ l volumes with 100 200 ng of amplified DNA products, 25U ApaI or 5U $B$ siEI(New England Biolabs, Beverly, MA, USA), $2 \mu \mathrm{l}$ $10 \times$ digestion buffer, $0.2 \mu \mathrm{l}$ bovine serum albumin and corresponding amount of water. Digestion mixtures were incubated for $0.5-1 \mathrm{~h}$ at $37^{\circ} \mathrm{C}$ for $A p a \mathrm{I}$ or at $60^{\circ} \mathrm{C}$ for BsiEI.
The resulting fragments were separated on $2 \%$ agarose gels and visualized under UV light after ethidium bromide staining, with a 100bp DNA ladder for fragment size comparison.

\section{RESULT}

\section{Sequence Analyses}

An extensive analysis of database entries of yeast species tested in this study was performed with respect to calculated fragment lengths of the D1/D2 regions generated by commercially available restriction enzymes. Minor differences in calculated lengths of PCR products were observed. Finally, $A p a \mathrm{I}$ and BsiEI were selected to be evaluated in experiment. Predicted fragment lengths of ApaI and BsiEI-digested PCR products are given in Table 1. ApaI was expected to cut the PCR amplicons of $C$. albicans and C. dubliniensis into two fragments, but leave those of other yeast species intact. BsiEI was selected to digest the amplicon of $C$. albicans into two fragments and those of $C$. dubliniensis would remain undigested. Thus two related Candida species can be identified and differentiated by distinctive and specific RFLP patterns.

Table 1. Comparison of PCR-RFLP assays to differentiate between C.albicans and C. dubliniensis

\begin{tabular}{|c|c|c|c|c|}
\hline $\begin{array}{l}\text { Target of PCR amplification } \\
\text { and primers }\end{array}$ & $\begin{array}{l}\text { Length of PCR } \\
\text { products (bp) } \\
\text { CA / CD }\end{array}$ & $\begin{array}{c}\text { Fragments' length after enzymatic digestion } \\
\text { (bp) } \\
\text { Enzyme: CA / CD }\end{array}$ & $\begin{array}{l}\text { No. of isolates tested } \\
\text { CA / CD }\end{array}$ & $\overline{\text { Reference }}$ \\
\hline ITS region: ITS5 and NL4 & approximately 1200 & $\begin{array}{l}\text { DdeI: } \quad 450,350,210,150 / 450,350,210,110 \\
\text { BfaI and HaeIII: differentiable but not specified }\end{array}$ & $78 / 10$ & 8 \\
\hline ITS region:CA-INT-L(R) & approximately 600 & DdeI: one fragment / two fragments & $8 / 2$ & 13 \\
\hline V3 region: CA25SV3L(R) & approximately 500 & HaeIII: differentiable but not specified & $8 / 2$ & 13 \\
\hline ITS2 region: ITS3 and ITS4 & approximately 340 & $\begin{array}{l}\text { NspBII: approximately } 160,180 / 340 \\
\text { BsmAI: approximately } 340 / 100,240\end{array}$ & $17 / 8$ & 19 \\
\hline ITS2 region: CTSF and CTSR & $345 / 350$ & MspA1I: $35,143,167 / 35,315$ & $1 / 9$ & 6 \\
\hline ITS region: UNI1 and UNI2 & $586 / 589$ & HрyF10VI: 141, 184, 261 / 264, 325 & $61 / 23$ & 1 \\
\hline ITS region: ITS1 and ITS4 & $540 / 540$ & $B \ln \mathrm{I}: 540 / 200,340$ & $146 / 12$ & 14 \\
\hline D1-D2 region: NL-1 and NL-4 & $615 / 614$ & $\begin{array}{l}\text { ApaI: } 134,481 / 134,480 \\
\text { BsiEI: } 181,434 / 614\end{array}$ & $43 / 15$ & $\begin{array}{l}\text { This } \\
\text { study }\end{array}$ \\
\hline
\end{tabular}

CA : C. albicans, CD : C. dubliniensis

\section{PCR Amplification of D1/D2 Regions}

As shown in Fig.1, intended DNA fragments of all reference strains were successfully amplified with primers NL1 and NL-4. PCR products were found to reach 550-600 bp in length as predicted from sequence analysis. However, most tested species, except $C$. lusitaniae, were inseparable due to similar PCR amplicon sizes. 


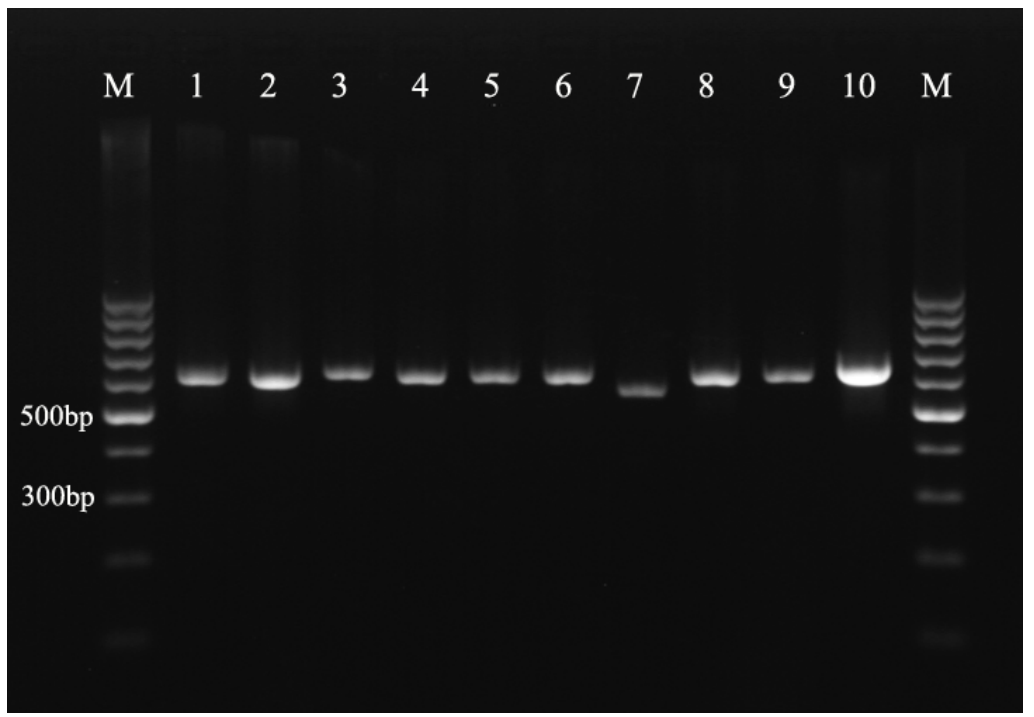

Figure 1. PCR products from 10 yeast species: Lane 1: C. albicans (SC 5314); Lane 2: C. dubliniensis (CBS 7987); Lane 3: C. glabrata (ATCC 2001); Lane 4: C. guilliermondii (CBS 6021); Lane 5: C. kefyr (CBS 6432); Lane 6: $C$. krusei (ATCC 6258); Lane 7: C. lusitaniae (CBS 6936); Lane 8: C. parapsilosis (ATCC 22019); Lane 9: C. tropicalis (CBS 8072); Lane 10: $T$. asahii (CBS 2479) ; Lane M: 100-bp ladder.

\section{RFLP Analyses of Reference Strains}

When digested with ApaI, D1/D2 regions of C. albicans and C. dubliniensis strains shared the same restriction pattern, with two bands of almost identical sizes (134bp, 481bp for C. albicans and 134bp, 480bp for C. dubliniensis) (Fig.2). Nevertheless, amplicons of other yeast strains were undigested by ApaI, which easily distinguished $C$. albicans and $C$. dubliniensis from other tested species. Digestion of the D1/D2 region with BsiEI generated distinctive restriction profiles for $C$. albicans: two fragments of
$181 \mathrm{bp}$ and 434bp (Fig.3). In addition, BsiEI also cut into two fragments the PCR-products of C. glabrata (149bp and 475bp), $C$. krusei (59bp and 548bp) and C. lusitaniae (126bp and 433bp). As was seen in Fig.3, the differences in fragment lengths were sufficient to discriminate C. albicans from C. glabrata, C. krusei and $C$. lusitaniae. Other tested species were undigested by BsiEI, including $C$. dubliniensis. Therefore, two separate enzymatic digestions produced species-specific RFLP profiles for C. albicans and C. dubliniensis.

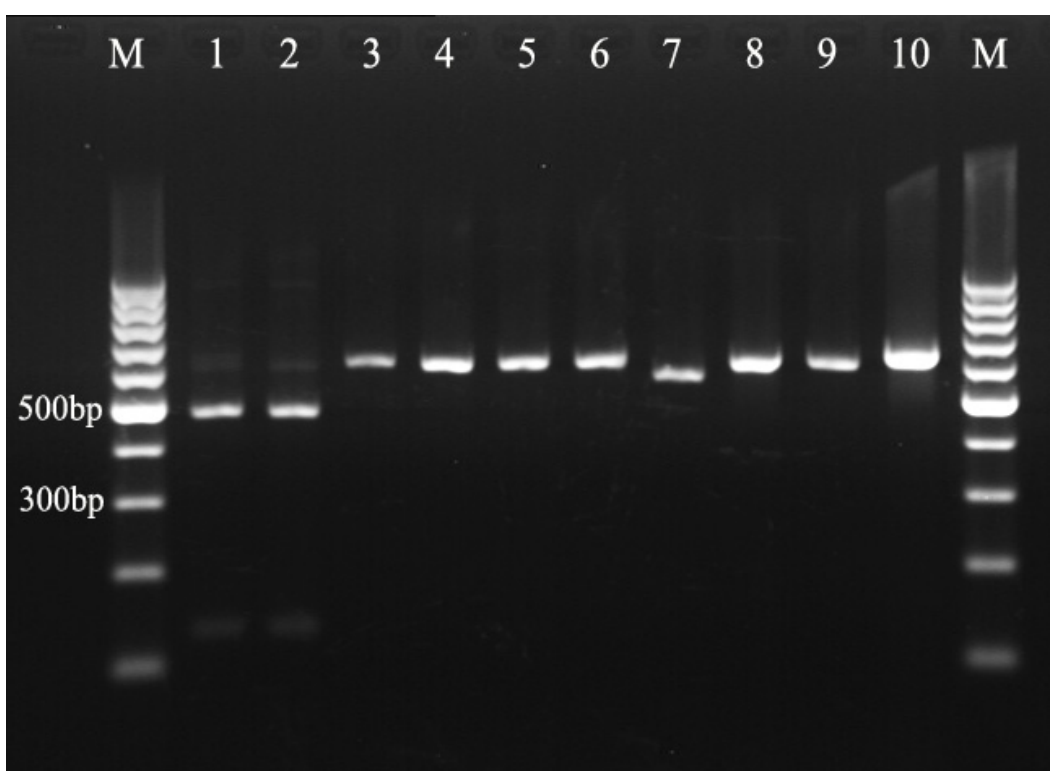

Figure 2. Restriction digestion of PCR products of reference yeast strains with ApaI : Lane 1: C. albicans (SC 5314); Lane 2: C. dubliniensis (CBS 7987); Lane 3: C. glabrata (ATCC 2001); Lane 4: C. guilliermondii (CBS 6021); Lane 5: C. kefyr (CBS 6432); Lane 6: C. krusei (ATCC 6258); Lane 7: C. lusitaniae (CBS 6936); Lane 8: C. parapsilosis (ATCC 22019); Lane 9: C. tropicalis (CBS 8072); Lane 10: T. asahii (CBS 2479) ; Lane M: 100-bp ladder. 


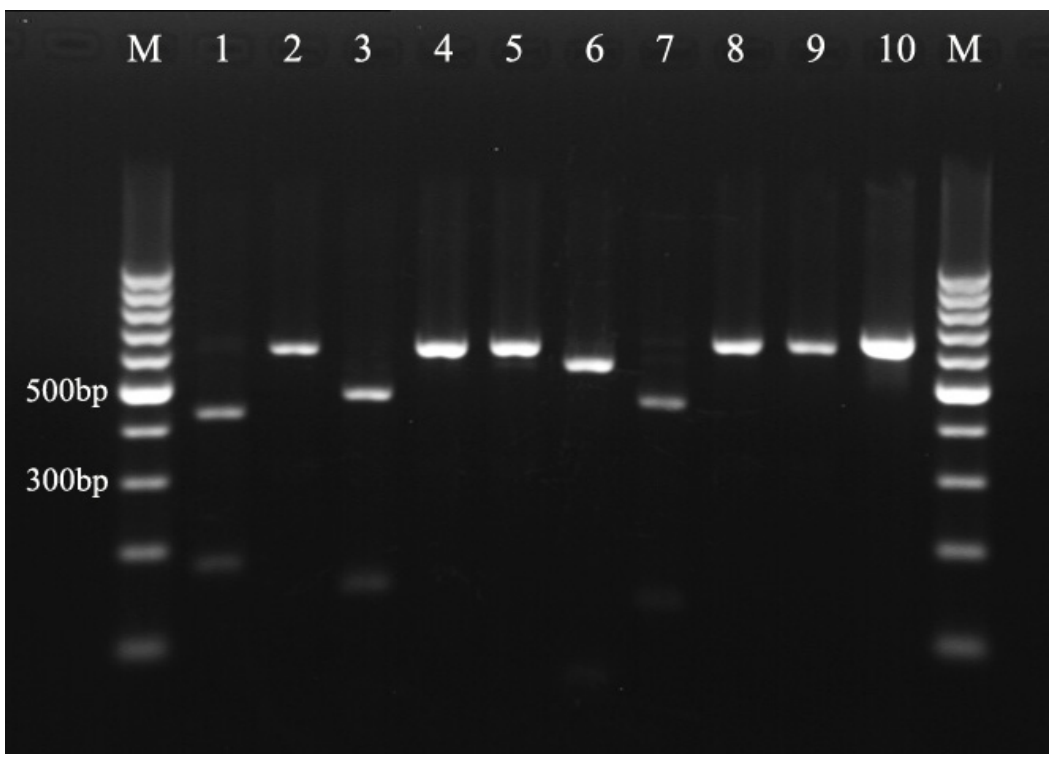

Figure 3. Restriction digestion of PCR products of reference yeast strains with BsiEI : Lane 1: C. albicans (SC 5314); Lane 2: C. dubliniensis (CBS 7987); Lane 3: C. glabrata (ATCC 2001); Lane 4: C. guilliermondii (CBS 6021); Lane 5: C. kefyr (CBS 6432); Lane 6: C. krusei (ATCC 6258); Lane 7: C. lusitaniae (CBS 6936); Lane 8: C. parapsilosis (ATCC 22019); Lane 9: C. tropicalis (CBS 8072); Lane 10: T. asahii (CBS 2479) ; Lane M: 100-bp ladder.

\section{Evaluation for Intra-species Variation of Restriction Sites}

To assess intra-species variability of the two restriction sites, a total of 56 clinical isolates of $C$. albicans and $C$. dubliniensis were also investigated. Most tested isolates, after digestion with $A p a \mathrm{I}$ and BsiEI respectively, showed identical and consistent RFLP patterns to their respective reference strains (data not shown). However, one of the 14 presumptive C. dubliniensis isolates showed RFLP pattern indicative of $C$. albicans. Further sequencing of the D1/D2 region of this isolate confirmed the identification of C. albicans.

\section{DISCUSSION}

Rapid and accurate identification of $C$. dubliniensis is crucial for the study of epidemiology and clinical management of infections caused by this opportunistic pathogen. However, this is hampered by lack of easy and reliable methods for definite identification. Most phenotypic methods are presumptive and often subject to error (28). Although several commercial identification systems such as Vitek 2 system, have demonstrated useful in separation of $C$. albicans and $C$. dubliniensis, results are not always reliable as was seen in our study $(3,12,23)$. Confirmatory identification of $C$. dubliniensis always requires the molecular methods.

PCR-RFLP assays have been successfully applied to the identification of Candida species $(17,22,29)$. Compared with other molecular methods, PCR-RFLP analysis is generally easy and rapid to perform. Although more complex RFLP methods have previously been used for the identification of $C$. dubliniensis, their use may be limited since they were timeconsuming or the results were difficult to interpret (18). Thus in this study, simpler but more advantageous PCR-RFLP is preferred due to its increased applicability in clinical laboratories.

Ribosomal regions, such as the internal transcribed spacer (ITS) region and $28 \mathrm{~S}$ rDNA, exhibit a low intraspecific polymorphism and a high interspecific variability, making them ideal targets for species identification purposes (9). In this study, we selected the D1/D2 variable region at the 5' end of the $28 \mathrm{~S}$ rDNA gene as target for PCR amplification. Sequencing of this region has been demonstrated to be sufficient for accurate identification of most yeast species (11). Between $C$. albicans and $C$. dubliniensis, there are 13 nucleotide differences in the region D1/D2, sufficiently variable for reliable differentiation. Two enzymes, ApaI and $B s i E \mathrm{I}$, were selected based on the restriction profiles generated 
by these nucleotide differences. Despite that only a limited number of $C$. albicans and $C$. dubliniensis isolates were investigated, those restriction sites for ApaI and BsiEI seemed to be well conserved in these two species.

Several PCR-RFLP assays have been described so far to discriminate between C. albicans and C. dubliniensis (Table 1). Irobi et al amplified the ITS regions (ITS1, 5.8S, ITS2) of several medically important Candida species, including $C$. dubliniensis (8). Further RFLP analysis with BfaI, DdeI or HaeIII revealed distinct differences between the two species. McCullough et al amplified the ITS regions and restricted them with DdeI. C. albicans produced one fragment while $C$. dubliniensis produced two fragments (13). In the same study, McCullough and his group also targeted the V3 region of 25S/28S rDNA and cut the PCR amplicons with HaeIII; the discrimination could be made based on fragments of different sizes. Park and his co-authors amplified a conserved part of the 5.8S rDNA, the adjacent ITS2 region and a part of 28S rDNA. The differentiation was achieved by analysis of the PCR products with BsmAI (C. dubliniensis-specific) and NspBIII (C. albicans-specific) (19). Three other PCR-RFLP assays also used a similar strategy by targeting a part or whole of the ITS region $(1,6,14)$. All these methods proved effective for accurate identification. In comparison, our study used a slightly different strategy. We first identified a restriction site for ApaI which was specific to both species, instantly separating them from other yeast species. Subsequently BsiEI was found to produce $C$. albicans specific pattern and $C$. dubliniensis was identified by absence of the restriction site.

An advantage of the method described here is the stable and easy-to-read RFLP patterns. Unlike previous reports, this method involves only one or two DNA fragments. Besides, it is a simple and rapid method to perform. With the aid of timesaving restriction enzymes, the whole process can be accomplished in less than $6 \mathrm{~h}$, requiring no sophisticated equipments except a conventional thermal cycler. Considering that DNA sequencer may not be readily available to most clinical laboratories, this molecular method is applicable for unequivocal identification and differentiation of $C$. albicans and C. dubliniensis.

\section{ACKNOWLEDGEMENTS}

The authors report no conflicts of interest.

\section{REFERENCES}

1. Ahmad, S.; Khan, Z.; Mokaddas, E.; Khan, Z.A. (2004). Isolation and molecular identification of Candida dubliniensis from non-human immunodeficiency virus-infected patients in Kuwait. J Med Microbiol. 53(Pt7): 633-637.

2. Akgül, O.;Cerikçioğlu, N. (2009). Hypertonic sabouraud dextrose agar as a substrate for differentiation of Candida dubliniensis. Mycopathologia. 167(6):357-359.

3. Cárdenes-Perera, C.D.; Torres-Lana, A.; Alonso-Vargas, R.; MoraguesTosantas, M.D.; Pontón-San Emeterio, J.;Quindós-Andrés, G.; ArévaloMorales, M.P. (2004). Evaluation of API ID 32C and Vitek-2 to identify Candida dubliniensis. Diagn Microbiol Infect Dis. 50(3): 219-221.

4. Edmond, M.B.; Wallace, S.E.; McClish, D.K.; Pfaller, M.A.; Jones, R.N.; Wenzel, R.P. (1999). Nosocomial bloodstream infections in United States hospitals: a three-year analysis. Clin Infec Dis. 29(2): 239-244.

5. Gales, A.C.; Pfaller, M.A.; Houston, A.K.; Joly, S.; Sullivan, D.J.; Coleman, D.C.; Soll, D.R. (1999). Identification of Candida dubliniensis based on temperature and utilization of xylose and $\alpha$-methyl-D-glucoside as determined with the API 20C AUX and Vitek YBC systems. J Clin Microbiol. 37(12): 3804-3808.

6. Graf, B.; Trost, A.; Eucker, J.; Göbel, U.B.; Adam, T. (2004). Rapid and simple differentiation of $C$. dubliniensis from C. albicans. Diagn Microbiol Infect Dis. 48(2): 149-151.

7. Gutierrez, J.; Morales, P.; Gonzalez, M.A.; Quindos, G. (2002). Candida dubliniensis, a new fungal pathogen. J Basic Microbiol. 42(3): 207-227.

8. Irobi, J.; Schoofs, A.; Goossens, H. (1999). Genetic identification of Candida species in HIV-positive patients using the polymerase chain reaction and restriction fragment polymorphism analysis of its DNA. Mol Cell Probes. 13(6): 401-406.

9. Iwen, P.C.; Hinrichs, S.H.; Rupp, M.E. (2002). Utilization of the internal transcribed spacer regions as molecular targets to detect and identify human fungal pathogens. Med Mycol, 40(1): 87-109.

10. Jewtuchowicz, V.M.; Mujica, M.T.; Brusca, M.I.; Sordelli, N.; Malzone, M.C.; Pola, S.J.; Iovannitti, C.A.; Rosa, A.C. (2008). Phenotypic and genotypic identification of Candida dubliniensis from subgingival sites 
in immunocompetent subjects in Argentina. Oral Microbiol Immunol. 23(6): 505-509.

11. Kurtzman, B.P.; Robnett, C.J. (1997). Identification of clinically important ascomycetous yeasts based on nucleotide divergence in the 50 end of the large-subunit (26S) ribosomal DNA gene. J Clin Microbiol. 35(5): 1216-1223.

12. Mähnss, B.; Stehr, F.; Scäfer, W.; Neuber, K. (2005). Comparison of standard phenotypic assays with a PCR method to discriminate Candida albicans and C. dubliniensis. Mycoses. 48(1): 55-61.

13. McCullough, M.J.; Clemons, K.V.; Stevens, D.A. (1999). Molecular and phenotypic characterization of genotypic Candida albicans subgroups and comparison with Candida dubliniensis and Candida stellatoidea. J Clin Microbiol. 37(2): 417-421.

14. Mirhendi, H.; Makimura, K.; Khoramizadeh, M.; Yamaguchi, H. (2006). A one-enzyme PCR-RFLP assay for identification of six medically important Candida Species. Nippon Ishinkin Gakkai Zasshi. 47(3): 225229.

15. Moran, G.P.; Sanglard, D.; Donnelly, S.M.; Shanley, D.B.; Sullivan, D.J.; Coleman, D.C. (1998). Identification and expression of multidrug transporters responsible for fluconazole resistance in Candida dubliniensis. Antimicrob Agents Chemother. 42(7): 1819-1830.

16. Moran, G.P.; Sullivan, D.J.; Henman, M.C.; McCreary, C.E.; Harrington, B.J.; Shanley, D.B.; Coleman, D.C. (1997). Antifungal drug susceptibilities of oral Candida dubliniensis isolates from human immunodeficiency virus (HIV)-infected and non-HIV-infected subjects and generation of stable fluconazole-resistant derivatives in vitro. Antimicrob Agents Chemother. 41(3): 617-623.

17. Mousavi, S.A.A.; Khalesi, E.; Shahidi Bonjar, G.H.; Aghighi, S.; Shaifi, F.; Aram, F. (2007). Rapid molecular diagnosis for Candida species using PCR-RFLP. Biotechnology. 6(4):583-587.

18. Neppelenbroek, K.H.; Campanha, N.H.; Spolidorio, D.M.P.; Spolidorio, L.C.; Seó, R.S.; Pavarina, A.C. (2006). Molecular fingerprinting methods for the discrimination between C. albicans and C. dubliniensis. Oral Disease.12 (3): 242-253.

19. Park, S.; Wong, M.; Marras, S.A.E.; Cross E.W.; Kiehn T.E.; Chaturvedi V.; Tyagi, S.; Perlin D.S. (2000). Rapid identification of Candida dubliniensis using a species-specific molecular probe. J Clin Microbiol.
38(8): 2829-2836.

20. Pfaller, M.A.; Diekema, D.J. (2007). Epidemiology of invasive candidiasis: a persistent public health problem. Clin Micobio Rev. 20(1): 133-163.

21. Pfaller, M.A.; Jones, R.N.; Messer, S.A.; Edmond, M.B.; Wenzel, R.P. (1998) National surveillance of nosocomial blood stream infection due to Candida albicans: frequency of occurrence and antifungal susceptibility in the SCOPE Program. Diagn Microbiol Infect Dis. 31(1): 327-332.

22. Pinto, P.M.; Resende, M.A.; Koga-Ito C.Y.; Ferreira, J.A.; Tendler, M. (2004). rDNA-RFLP identification of Candida species in immunocompromised and seriously diseased patients. Can J Microbiol. 50(7):514-520.

23. Pincus, D.H.; Coleman, D.C.; Pruitt, W.R.; Padhye, A.A.; Salkin, I.F.; Geimer, M.;Bassel, A.; Sullivan, D.J.; Clarke, M.; Hearn, V. (1999). Rapid identification of Candida dubliniensis with commercial yeast identification systems. J Clin Microbiol. 37(11):3533-3539.

24. Ruhnke, M.; Schmidt-Westhausen, A.; Morschhauser, J. (2000). Development of simultaneous resistance to fluconazole in Candida albicans and Candida dubliniensis in a patient with AIDS. J Antimicrob Chemother. 46(2): 291-295.

25. Rocha, B.A.; Barbaro Del Negro G.M.; Yamamoto, L.; de Souza, M.V.B.; Precioso, A.R.; Okay, T.S. (2008). Identification and differentiation of Candida species from paediatric patients by random amplified polymorphic DNA. Rev Soc Bras Med Trop. 41(1): 1-5.

26. Sullivan, D.J.; Westerneng, T.J.; Haynes, K.A.; Bennett, D.E.; Coleman, D.C. (1995). Candida dubliniensis sp. nov.: phenotypic and molecular characterisation of a novel species associated with oral candidosis in HIV infected individuals. Microbiology. 141(7): 1507-1521.

27. Sullivan, D.J.; Coleman, D.C. (1998). Candida dubliniensis: characteristics and identification. J Clin Microbiol. 36(2): 329-334.

28. Tintelnot, K.; Haase, G.; Seibold, M.; Bergmann, F.; Staemmler, M.; Franz, T.; Naumann, D. (2000). Evaluation of phenotypic markers for selection and identification of C. dubliniensis. J Clin Microbiol. 38(4):1599-1608.

29. Trost, A.; Graf, B; Eucker, J.; Sezer, O.; Possinger, K.; Göbel, U.; Adam, T. (2004). Identification of clinically relevant yeasts by PCR/RFLP. $J$ Microbio Methods. 56(2): 201-211. 